\title{
NOÇÕES BÁSICAS DE PRIMEIROS SOCORROS: RELATO DE EXPERIÊNCIA DE UM PROJETO DE EXTENSÃO RURAL
}

\section{Basic notions of first aid: experience report on a rural extension project \\ Nociones básicas de primeros auxilios: relato de experiencia de un proyecto de extensión rural}

\author{
Caren da Silva Bertoldo (iD \\ Universidade Federal de Santa Maria - UFSM - Santa Maria (RS) - Brasil \\ Daiana Cristina Wickert (iD \\ Universidade Federal de Santa Maria - UFSM - Santa Maria (RS) - Brasil
}

Victória de Quadros Severo Maciel iD

Universidade Federal de Santa Maria - UFSM - Santa Maria (RS) - Brasil

Catiele Piccin (iD

Programa de Residência Multiprofissional em Saúde do Hospital Santa Cruz - Santa Cruz do Sul (RS) - Brasil

Jordana Lima Silva iD

Universidade Federal de Santa Maria - UFSM - Santa Maria (RS) - Brasil

Oclaris Lopes Munhoz (iD

Universidade Federal de Santa Maria - UFSM - Santa Maria (RS) - Brasil

Maria Denise Schimith (D)

Universidade Federal de Santa Maria - UFSM - Santa Maria (RS) - Brasil

\section{RESUMO}

Objetivo: Relatar a experiência de discentes do Programa de Educação Tutorial (PET) da graduação em Enfermagem no desenvolvimento de capacitações acerca de noções básicas de primeiros socorros em área rural. Síntese dos dados: Trata-se de um relato de experiência a partir da vivência prática de discentes do PET Enfermagem de uma universidade da região central do estado do Rio Grande do Sul (RS), Brasil, no desenvolvimento de capacitações acerca dos primeiros socorros para produtores rurais. As atividades ocorreram de agosto de 2016 a dezembro de 2017. Realizaram-se encontros nos municípios de Toropi, Dilermando de Aguiar, Ivorá, Silveira Martins e Faxinal do Soturno, localizados na região central do RS. Os temas abordados foram: choques elétricos, acidentes com animais peçonhentos, intoxicação por agrotóxicos, queimaduras, obstrução de vias áreas, afogamento e parada cardiorrespiratória (PCR). Acredita-se que atividades extramuros da universidade, promovidas por meio de projetos de extensão, propiciam ao discente complementar a sua formação, enquanto profissional da saúde, ao mesmo tempo que fomentam as ações de educação em saúde, facilitando o acesso à informação de populações rurais, caracterizadas, muitas vezes, com baixo nível de conhecimento devido ao difícil acesso. Conclusão: Ações educativas, como as descritas neste relato, possibilitam a troca de saberes entre os envolvidos, promovendo a disseminação de conhecimento acerca das situações de emergência e também o desenvolvimento das habilidades relacionadas às práticas de enfermagem. A capacitação da população leiga nesse assunto possui extrema importância no atendimento inicial em situações de emergência.

Descritores: Educação em Saúde; Enfermagem; População Rural; Primeiros Socorros; Reanimação Cardiopulmonar

\section{ABSTRACT}

Objective: To report on the experience of Nursing students enrolled in a Tutorial Education Program (Programa de Educação Tutorial - PET) towards the development of training on the basic notions of first aid in rural areas. Data synthesis: This is an experience report on the practical experience of nursing students enrolled in the PET of a university in the Central Region of the State of Rio Grande do Sul (RS), Brazil, towards the development of training on first aid for rural producers. The activities took place from August 2016 to December 2017. Meetings were held in the municipalities of Toropi, Dilermando de Aguiar, Ivorá, Silveira

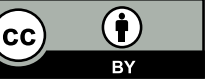


Martins and Faxinal do Soturno, located in the central region of RS. The subjects addressed were: electric shocks, accidents with venomous animals, pesticide poisoning, burns, airway obstruction, drowning and cardiorespiratory arrest (CRA). The activities performed outside the university through extension programs are believed to provide the student with complementary training as a health professional and promote health education actions, and facilitate access to information for rural populations who often have low levels of knowledge due to difficult access. Conclusion: Educational actions such as those described in this report make it possible to exchange knowledge among the people involved and hence promote the dissemination of knowledge about emergency situations and also the development of skills related to nursing practices. Training the lay population on this subject is extremely important for initial care in emergency situations.

Descriptors: Health Education; Nursing; Rural Population; First aid; Cardiopulmonary resuscitation.

\section{RESUMEN}

Objetivo: Relatar la experiencia de discentes del Programa de Educación Tutorial (PET) del grado de Enfermería para el desarrollo de capacitaciones sobre las nociones básicas de primeros auxilios en la zona rural. Síntesis de los datos: Se trata de un relato de experiencia a partir de la vivencia práctica de los discentes del PET Enfermería de una universidad de la región central del estado de Rio Grande do Sul (RS), Brasil, para el desarrollo de las capacitaciones sobre los primeros auxilios para los productores rurales. Las actividades se dieron entre agosto de 2016 y diciembre de 2017. Se realizaron encuentros en los municipios de Toropi, Dilermando de Aguiar, Ivorá, Silveira Martins y Faxinal do Soturno localizados en la región central de RS. Los temas abordados fueron: los choques eléctricos, los accidentes con animales pezoñentos, la intoxicación por agrotóxicos, las quemaduras, la obstrucción de las vías aéreas, el ahogamiento y la parada cardiorrespiratoria (PCR). Se cree que las actividades extramuros de la universidad que son promocionadas por los proyectos de extensión permiten el discente complementar su formación de profesional sanitario a la hora que fomentan las acciones de educación en salud que facilita el acceso a la información de poblaciones rurales caracterizadas muchas veces por el bajo nivel de conocimiento a causa del acceso difícil. Conclusión: Acciones educativas como las descritas en ese relato permiten el cambio de saberes entre los involucrados promocionando la diseminación del conocimiento sobre las situaciones de emergencia y también el desarrollo de las habilidades relacionadas con las prácticas de enfermería. La capacitación de la población lega en el tema tiene extrema importancia para la atención inicial de situaciones de emergencia.

Descriptores: Educación en Salud; Enfermería; Población Rural; Primeros Auxilios; Reanimación Cardiopulmonar.

\section{INTRODUÇÃO}

De acordo com dados da Organização Mundial de Saúde, as causas externas são responsáveis por 9\% da mortalidade total, sendo os principais responsáveis por esses óbitos: envenenamento, afogamento, queimaduras, choques elétricos, acidentes de trânsito, suicídios, quedas e homicídios. Entre os mais acometidos, estão jovens, entre 15 e 29 anos $^{(1)}$. No Brasil, a taxa de mortalidade por causas externas representa $13 \%$, constituindo a terceira causa de óbitos, ficando atrás somente das doenças crônicas não transmissíveis e transmissíveis, respectivamente ${ }^{(1)}$.

As causas externas de morbidade e mortalidade compõem o capítulo $X X$ da $10^{\mathrm{a}}$ revisão da Classificação Internacional de Doenças (CID-10), sendo definidas como traumas, lesões e danos de saúde, de início súbito e decorrente de violência, envenenamento ou causas extrínsecas ${ }^{(2,3)}$. Também estão incluídos nesse grupo os acidentes de trânsito, em domicílio e no ambiente de trabalho; as situações de emergência provenientes de quedas, afogamentos, envenenamentos e queimaduras, além das ocorrências ocasionadas por circunstâncias ambientais (de natureza mecânica, química, térmica, elétrica e/ou radiação) ${ }^{(4)}$.

Embora as ocorrências de situações emergenciais sejam frequentes, verifica-se que o ensino de primeiros socorros é pouco difundido, já que a maioria das pessoas desconhece as noções básicas de primeiros socorros ${ }^{(5)}$.

A falta de capacitação pode ser agravada quando associada a locais de difícil acesso, como as comunidades rurais. As dificuldades de acesso estão presentes em variados contextos, seja em grandes centros urbanos, onde os recursos estão disponíveis, seja em locais com baixos níveis assistenciais, como a zona rural, onde se tornam ainda mais necessárias as capacitações para situações de emergência( ${ }^{(6)}$.

Nessa perspectiva, a qualquer momento pode-se ser surpreendido por uma situação de emergência e socorro imediato, de modo que a qualidade dos primeiros socorros ofertados é importante para elevar as chances de sobrevida e minimizar a piora do estado clínico do indivíduo até a chegada do serviço especializado ao local. Para isso, conhecimento sobre como prestar socorro e tomar as decisões corretas, avaliando o estado e o local onde a vítima se encontra, e solicitar ajudar adequada, sempre respeitando as suas limitações, se faz necessário a toda a população, visto que práticas de primeiros socorros inadequadas estão relacionadas com os danos que uma assistência equivocada pode resultar ${ }^{(5)}$. 
Pode-se definir os primeiros socorros como sendo os cuidados imediatos que devem ser prestados, rapidamente, a uma pessoa, seja ela vítima de acidentes seja de mal súbito, cujo estado clínico a põe em risco eminente de morte. O objetivo desse atendimento é manter os sinais vitais e garantir a vida até a chegada de atendimento especializado(5).

Embora o acesso à saúde seja um direito reconhecido, existem barreiras que o inviabilizam, entre as quais se destacam: as restrições socioculturais e socioeconômicas, além da limitação de informações referentes às necessidades de saúde e direitos à saúde, bem como a disponibilidade de serviços ${ }^{(7)}$. Ao se refletir acerca do acesso aos serviços de saúde em áreas rurais, os problemas são ainda maiores, pois, além das restrições já citadas, possuem o fator geográfico e espacial, que dificultam ainda mais o acesso aos serviços de saúde.

Nesse sentido, salienta-se a relevância da problemática, partindo-se do princípio de que treinar e capacitar a população, nos diversos cenários de inserção, pode ser uma estratégia para prevenção, avaliação e condutas corretas em uma primeira abordagem, propiciando a redução dos danos e agravos de saúde em situações de emergência( ${ }^{(8)}$.

Para isso, a educação em saúde constitui-se como uma ferramenta eficaz para disseminar o aprendizado e a autonomia no cuidado com a vida, pois permite desenvolver e aprimorar a promoção e a prevenção de agravos. Ações educativas possibilitam a compreensão e fornecem subsídios para solucionar os problemas de saúde da sociedade e melhorar a qualidade de vida ${ }^{(9)}$.

O grande impacto das mortes por causas externas nas taxas de morbimortalidade da população do país acaba se configurando como um problema de saúde pública. Tal fato ocasionou a criação da Política Nacional de Redução da Morbimortalidade por Acidente e Violência, em 2001, a qual evidencia os princípios da promoção à saúde em relação à capacidade da população em desenvolver, melhorar e conservar condições e hábitos saudáveis ${ }^{(10)}$, sendo uma de suas diretrizes a ampliação e a consolidação acerca dos primeiros-socorros.

Ainda que as causas externas sejam uma das principais causas de mortalidade, nem sempre elas resultam em óbito. Por vezes, os acidentes por causas externas ocasionam hospitalização das vítimas, podendo gerar incapacidades, temporárias ou permanentes, e consequências para a saúde ${ }^{(11)}$. Dessa forma, a promoção da saúde torna-se indispensável, uma vez que possibilita que profissionais da saúde dialoguem com a população, fazendo com que todos sejam protagonistas na proteção e na qualidade de vida e saúde, resultando tanto no empoderamento individual como comunitário(12).

Considerando que o socorrista possa ser uma pessoa leiga, torna-se importante a existência de projetos de educação em saúde. A exemplo disso, a capacitação e treinamento em primeiros socorros no contexto extra-hospitalar e, principalmente, extramuros da universidade, compreendendo também o meio rural, possibilita que esse primeiro atendimento seja realizado da maneira mais correta possível, pois condutas incorretas podem agravar ainda mais o estado da vítima ${ }^{(13)}$.

Partindo dessas considerações, o presente artigo tem como objetivo relatar a experiência de discentes do Programa de Educação Tutorial (PET) do curso de graduação em Enfermagem no desenvolvimento de capacitações acerca de noções básicas de primeiros socorros em área rural.

\section{SÍNTESE DOS DADOS}

Trata-se de um relato de experiência a partir da vivência prática de discentes do PET Enfermagem no desenvolvimento de capacitações acerca de noções básicas de primeiros socorros para moradores de áreas rurais. O projeto a que essas atividades estão vinculadas intitula-se "Extensão Rural" e foi criado no ano de 2016, a partir de uma parceria proposta pelo PET do curso de Engenharia Elétrica ao PET Enfermagem da Universidade Federal de Santa Maria (UFSM).

A referida universidade tem como sede o município de Santa Maria, possuindo ainda mais três campi fora de sede, nas cidades de Frederico Westphalen, Palmeira das Missões e Cachoeira do Sul. De acordo com dados da instituição, atualmente, a UFSM possui 130 cursos de graduação, 103 cursos de pós-graduação e um programa de pós-doutorado. Além disso, oferece 27 cursos técnicos pós-médio e cinco cursos para ensino médio ${ }^{(14)}$.

O projeto conta com a participação de mais dois grupos PET, de Odontologia e de Educação Física. A união entre as diferentes áreas de conhecimento fortalece o projeto e as atividades desenvolvidas, uma vez que permite a abordagem de diversas lacunas dentro da sociedade ${ }^{(15)}$. Este projeto visa capacitar e treinar moradores de comunidades rurais, de forma simples e de fácil entendimento, para executarem condutas adequadas em uma primeira abordagem às vítimas nas mais variadas possibilidades de emergências que o meio rural possa desencadear.

Dessa forma, buscou-se proporcionar troca de conhecimentos entre a comunidade rural das cidades do interior do Rio Grande do Sul e os estudantes universitários. Além de integrar os estudantes com a sociedade, a extensão universitária possibilita aliar ensino e pesquisa na busca pelo compartilhamento do conhecimento ${ }^{(16)}$. 
Inicialmente, o projeto Extensão Rural era desenvolvido por meio de oficinas de instalações elétricas, em que se abordava temas como segurança e eficiência energética, com o intuito de melhorar a qualidade das instalações elétricas dos produtores rurais e de suas famílias. Assim, buscava-se informar aos agricultores sobre os métodos de segurança ao se trabalhar com energia elétrica. Em contrapartida, os produtores trouxeram relatos de situações emergenciais que vivenciaram, nas quais eram necessários cuidados de primeiros socorros. Diante disso, os acadêmicos do curso de Engenharia Elétrica, vinculados ao projeto, sentiram a necessidade de agregar conhecimento especializado em suas oficinas ao abordar a temática segurança em saúde, construindo um vínculo com os acadêmicos do curso de Enfermagem.

As atividades desenvolvidas pelos discentes do PET Enfermagem consistiram na capacitação, instrução e treinamento de noções básicas de primeiros socorros frente a situações cotidianas da vivência em meio rural. Por vezes, as pessoas não possuem conhecimentos necessários para a realização dos primeiros cuidados, assim como desconhecem a forma correta de proceder em situações de emergência. O conhecimento, a compreensão e o treinamento sobre a abordagem mais correta e eficaz são imprescindíveis nessas situações. A avaliação da vítima, do mesmo modo que a forma de atendimento ainda no primeiro momento, pode salvar vidas e/ou impedir maiores agravos ${ }^{(13)}$.

Nesse sentido, o conhecimento acerca dos primeiros socorros se faz necessário nos diferentes grupos da população, uma vez que tais situações podem ocorrer nos mais variados cenários, inclusive no meio rural. Assim sendo, o discernimento nessa temática é de suma importância, não apenas para os profissionais da área da saúde, mas também para os distintos segmentos sociais e profissionais ${ }^{(15)}$.

Partindo desse pressuposto, as atividades foram organizadas previamente por meio de reuniões compostas por todos os integrantes dos grupos PET e as pautas abordadas consistiram na distribuição de tarefas. Os municípios em que se realizaram as atividades foram Toropi, Dilermando de Aguiar, Ivorá, Silveira Martins e Faxinal do Soturno, localizados na região central do Rio Grande do Sul. A escolha desses municípios ocorreu por serem a cidade natal de algum dos acadêmicos participantes da atividade, facilitando o contato prévio com as entidades administrativas da cidade. Caso não houvesse nenhum vínculo com a comunidade, os integrantes do grupo PET Engenharia Elétrica responsabilizavam-se por contatar a prefeitura local e apresentar a proposta, bem como os requisitos que a cidade devia cumprir para que se efetivasse a ação.

O público-alvo das atividades constituiu-se de agricultores(as) residentes na comunidade rural dos municípios supracitados. O critério de inclusão era ser agricultor(a), e de exclusão, ser menor de idade e não estar acompanhado pelos pais. A delimitação do número de participantes ocorreu de acordo com a capacidade do espaço oferecido pelo município. Em média, cada encontro contou com a participação de 10 agricultores, totalizando média de 50 agricultores, entre homens e mulheres que foram previamente convidados pela prefeitura municipal e interessaram-se em participar.

No total, foram realizados cinco encontros, sendo um encontro em cada cidade e todas próximas da cidade sede da universidade. As atividades ocorreram no decorrer do segundo semestre letivo de 2016 e ao longo do ano de 2017. Cada encontro teve duração aproximada de cinco horas.

A divulgação do projeto, entre os munícipes, assim como a organização do espaço para realização da atividade e coffee break, era de responsabilidade dos representantes municipais. O deslocamento dos participantes do projeto até a cidade foi realizado via transporte cedido ou alugado pela instituição de ensino.

Os integrantes do grupo PET Enfermagem organizaram sua apresentação dentro do limite de tempo de 1h30, tempo pré-determinado em reunião, objetivando melhor organização da tarde e propiciando que cada grupo PET dispusesse de tempo para desenvolver seu planejamento de atividades. Utilizaram-se slides ilustrativos a fim de facilitar a visualização da ação por parte dos participantes, sendo intercalados com as falas dos acadêmicos.

As técnicas apresentadas pelos discentes do PET Enfermagem relacionavam-se com as seguintes temáticas: choques elétricos, acidentes com animais peçonhentos, intoxicação por agrotóxicos, queimaduras, obstrução de vias áreas, afogamento e parada cardiorrespiratória (PCR). Para isso, contou-se com a participação do público e com bonecos desenvolvidos pelo próprio grupo para demonstração prática de manobras relacionadas aos primeiros socorros. Por fim, realizaram-se atividades práticas de forma dinâmica e simples como, por exemplo, reproduzir a manobra de Reanimação Cardiopulmonar (RCP) e a manobra de Heimlich, facilitando o aprendizado.

Destaca-se, ainda, que o grupo PET desenvolveu um instrumento de avaliação contendo questões simples e rápidas que abrangeram os conteúdos, a apresentação audiovisual, as dinâmicas e conhecimento dos participantes sobre o tema. Além disso, havia um espaço para que os participantes pudessem registrar sugestões, se assim o quisessem. Esse instrumento possibilitou o feedback das atividades e objetivou avaliação e a melhoria constante do projeto. 
Por se tratar de um relato de experiência e visto que não há exposição dos envolvidos, não se fez necessária aprovação deste estudo pelo Comitê de Ética em Pesquisa. O projeto de extensão em que as atividades foram desenvolvidas está registrado no Gabinete de Projetos do Centro de Comunicação, Departamento de Eletrônica e Comunicação (ELC), sob o número 042870.

Tendo como objetivo a melhor compreensão dos temas abordados, serão apresentados a seguir subitens acerca das temáticas trabalhadas com os participantes.

\section{Parada Cardiorrespiratória}

Ao abordar a temática da parada cardiorrespiratória (PCR) foi apresentado aos participantes seu conceito, sinais e sintomas, e a forma de atuação frente a essa situação de emergência. A transmissão de conhecimento em primeiros socorros constitui-se como um importante fator para a qualidade do socorro imediato prestado às vítimas de incidentes, uma vez que o socorrista pode ser uma pessoa da população em geral, e qualificar esses indivíduos significa atribuir-Ihes confiança nas ações que realizam. Ademais, quando os indivíduos se encontram capacitados e seguros, eles ofertam socorro de melhor qualidade, minimizando as sequelas resultantes de primeiros socorros inadequados ${ }^{(13)}$.

Além disso, o substancial aumento das condições crônicas, em especial as que acometem o sistema circulatório, como insuficiência cardíaca (IC) e infarto agudo do miocárdio (IAM), é um problema de saúde pública que aponta para falhas na promoção da saúde. Ambas as enfermidades podem levar à PCR e, nesse caso, a correta realização da reanimação cardiopulmonar (RCP) pode diminuir as taxas de mortalidade e as chances de a vítima desenvolver alguma sequela. Sendo assim, é reafirmada a importância de se abordar e aprimorar esse tema junto à comunidade, em especial entre os que vivem no meio rural, visto que há maior demora na chegada do serviço especializado, o que pode trazer consequências ${ }^{(17)}$. Estudo realizado com o Serviço de Atendimento Móvel de Urgência (SAMU), no município de Teresina, evidenciou que o tempo de deslocamento das ambulâncias até o local do chamado, nas áreas rurais, é 20 minutos mais demorado do que quando comparado ao deslocamento em meio urbano aproximadamente ${ }^{(18)}$.

Associado à RCP, os acadêmicos do grupo PET Enfermagem ensinaram como realizar a desobstrução das vias áreas ou manobra de Heimlich, objetivando a expulsão de objeto ou líquidos que possam estar causando engasgo na vítima. A PCR está intrinsecamente relacionada com a obstrução das vias aéreas quando sua ocorrência se dá em crianças, ou seja, a obstrução das vias aéreas pode desencadear uma PCR ${ }^{(17)}$. Dessa forma, torna-se necessário realizar a desobstrução das vias áreas concomitante com a RCP.

No decorrer da abordagem da temática, possibilitou-se aos participantes a execução da técnica uns com os outros, podendo, assim, identificar o local correto de aplicar a força durante a manobra, bem como a forma correta de posicionar e movimentar a mão. No que se refere à PCR, a fim de melhor ilustrar a técnica correta, como o correto posicionamento do corpo e das mãos, e a profundidade e frequência das compressões, foram disponibilizados bonecos interativos construídos pelos integrantes do grupo PET Enfermagem.

A partir dessas práticas, proporcionou-se aos participantes uma simulação real de situações de primeiros socorros. Assim, constituiu-se uma proposta interativa e dinâmica, que possibilitou maior compreensão acerca dos temas abordados e da operacionalização das manobras de reanimação e engasgo.

\section{Intoxicação por Agrotóxicos}

Há 10 anos o Brasil está classificado como o país que mais consome produtos químicos, como os agrotóxicos, do mundo. Houve aumento expressivo da distribuição desse insumo, representando um agravante para a saúde pública, uma vez que possuem alto nível de toxicidade ambiental e humana, seja na atividade laboral, seja no consumo dos produtos agrícolas ${ }^{(19)}$.

Segundo dados do Programa de Análise de Resíduos de Agrotóxicos em Alimentos (PARA), 38,3\% dos alimentos analisados apresentaram resíduos de agrotóxicos dentro do Limite Máximo de Resíduos (LMR) estabelecido pela Anvisa. Além disso, 1,11\% das amostras monitoradas representam um potencial de risco agudo à saúde ${ }^{(20)}$. No que tange às notificações por intoxicação exógena registradas no Sistema de Informação de Agravos de Notificação (SINAN), só em 2017 foram 3.859 notificações de intoxicação por agrotóxico agrícola e 1.469 por agrotóxico doméstico(21).

Nesse ínterim, apresentaram-se os principais meios de intoxicação por agrotóxicos, visto que a gravidade do caso varia de acordo com o princípio ativo do produto, a dose absorvida e a forma como ocorreu a exposição. Frente ao exposto, torna-se fundamental empoderar os indivíduos que manuseiam esses produtos, pois os riscos inerentes à contaminação são amplos e complexos, podendo resultar no desenvolvimento de patologias graves, como o câncer ${ }^{(22) .}$ 
Além disso, houve um momento de conversa com os agricultores sobre as formas de prevenir a intoxicação por agrotóxicos, que consiste, basicamente, no uso de equipamento de proteção individual (EPI). Nessa oportunidade, foi destacada a importância da sua utilização, pois se sabe que, com frequência, os EPIs não são utilizados para o manuseio dos agrotóxicos, muitas vezes por serem desconfortáveis e pelo excesso de calor ao usar o macacão(23).

Dados da literatura apontam que, muitas vezes, os agricultores não utilizam os EPIs por acreditarem que ao manusear os agrotóxicos com roupas longas, chapéu e botas estão protegidos da ação nociva desses produtos, no entanto, tal afirmação está equivocada ${ }^{(23)}$. Portanto, o momento de apresentação dos EPIs para aplicação dos agrotóxicos se fez fundamental durante a atividade, enfatizando a necessidade e utilização. Para isso, os acadêmicos contaram com o auxílio de imagens ilustrativas que demonstravam cada equipamento, a forma de uso e sua função frente à prevenção da intoxicação por agrotóxicos.

Por fim, acerca da temática em questão, realizou-se sucinta capacitação dos participantes em como proceder nos casos em que a intoxicação por agrotóxicos já ocorrera. Essa parte da atividade consistiu na discussão dos principais procedimentos realizados a partir da exposição aguda aos agrotóxicos e também em como identificar os sinais e sintomas da exposição crônica.

Quando a intoxicação aguda acontece por via cutânea, as principais recomendações são: lavar a pele com água corrente e sabão, por dez minutos pelo menos; no caso de contato com os olhos, lavá-los com água corrente, por, no mínimo quinze, minutos, além de também remover as roupas e guardá-las em saco plástico, a fim de evitar que entrem em contato com outras pessoas ou animais. Com relação à intoxicação por via inalatória, recomendase afrouxar as roupas e retirar a vítima do local, levando-a para um ambiente arejado. Já no que diz respeito à intoxicação por via oral, deve-se ler as instruções do rótulo a fim de verificar a recomendação ou não da necessidade de provocar vômito. Além disso, salienta-se que, em todas as situações de exposição aguda aos agrotóxicos, a vítima deve ser encaminhada a um serviço de saúde especializado após a realização dos primeiros socorros ${ }^{(24)}$.

Ainda, de acordo com o manual de vigilância da saúde de populações expostas a agrotóxicos, os principais sinais e sintomas da intoxicação aguda são: cefaleia, tontura, náusea, vômito, fasciculação muscular, dificuldade respiratória e desorientação. Já a intoxicação crônica inclui sintomas como: paresias e paralisias reversíveis, pancitopenia e distúrbios neuropsicológicos ${ }^{(24)}$.

A aproximação do acadêmico de Enfermagem dessa população permite capacitar e sensibilizar os produtores rurais ao manejo correto dos agrotóxicos, possibilitando que fiquem mais atentos aos sinais e sintomas das intoxicações ${ }^{(25)}$. Para cada caso, a conduta pode ser diferente, no entanto o encaminhamento a um pronto atendimento ou hospital é necessário em todos os casos, para que ocorra a investigação e avaliação clínica, lembrando sempre da importância de relatar qual(is) o(s) agrotóxico(os) utilizado(s) ${ }^{(24)}$.

\section{Choque Elétrico}

Acerca deste assunto, durante as atividades realizadas, deu-se ênfase em ministrar aos agricultores o que deve ser feito em uma situação de choque elétrico, como desligar a corrente elétrica, o número do SAMU, observar se a pessoa está em PCR e se ela está sangrando. Ainda, trataram-se de questões relacionadas à gravidade do choque elétrico, que é determinado por variados fatores, dependendo da sua natureza (por exemplo, tomada ou raio), potência, local de entrada e saída, e a duração. Também, abordaram-se suas consequências, que variam de queimaduras, espasmos e alterações cardíacas até uma PCR.

A utilização da eletricidade exige precauções, que são desconhecidas ou menosprezadas pela maioria da população( ${ }^{(26)}$. O choque elétrico não produz alterações com consequências graves se não ultrapassar os valores críticos. No entanto, quando ultrapassados, ocorrem contrações musculares intensas, que podem impedir que a vítima liberte-se do contato com o circuito elétrico, podendo provocar asfixia e morte se o tórax for atingido(26).

Dados estatísticos mostram que o total geral de acidentes de origem elétrica (choque elétrico, incêndios por curto-circuito e descargas atmosféricas), no ano de 2017, foi de 1387 acidentes. Dos acidentes por choque elétrico, em 2017, 627 foram fatais. Destes, 98 ocorreram na região sul e 37 ocorreram no estado do Rio Grande do Sul. Em relação às localidades de acidentes por choque elétrico fatais, 218 ocorreram em ambientes residenciais e 50 na área rural, o que evidencia as falhas nas orientações à população.

Os dados relacionados às mortes por choque elétrico em decorrência de atividade profissional, em 2017, mostram que 72 mortes ocorreram em agricultores (terceiro maior número), sendo que, nas apurações destas, evidencia-se que há grande número de mortes por manuseio e instalações de bombas de poço e sucção(27). Assim, salienta-se a importância de instruir os agricultores acerca das técnicas de segurança ao realizar instalações elétricas, como certificar-se de que a fonte de energia está desligada, de que os fios utilizados são os adequados para a voltagem requerida, entre outras. Além disso, os dados elucidam que a realidade em que a população rural está inserida 
requer preparo e capacitação para agir frente às emergências relacionadas ao choque elétrico, enfatizando, mais uma vez, a importância dos primeiros socorros na vida dessas pessoas.

Em vista disso, atenta-se para os pilares da educação em saúde, a qual transpassa a verticalidade de informações e adentra no âmbito do compartilhamento de saberes. As experiências dos participantes são ouvidas e julgadas como importantes para construção conjunta do conhecimento. Assim, essa metodologia amplia a confiança transferida dos participantes aos acadêmicos, impulsionando a possibilidade de adesão às práticas e, consequentemente, mudanças de conduta ${ }^{(28)}$.

Assim, além da participação ativa e do retorno positivo dos participantes em relação à capacitação em primeiros socorros, destaca-se que o desenvolvimento da atividade permitiu aos acadêmicos em formação a experiência com o público rural e a interação com outros cursos, o que, por meio do currículo formal do curso, não é possibilitado. Além disso, instiga a criatividade para a criação no desenvolvimento da oficina e o aprofundamento técnico e científico dos temas abordados, constituindo um importante exercício para desenvolvimento pessoal e profissional dos envolvidos.

Esta experiência possibilitou aos acadêmicos a aproximação com a população rural, além de permitir que a comunidade rural tivesse contato com a temática dos primeiros socorros. Durante os encontros, percebeu-se a importância de atividades de extensão para esse público-alvo.

É importante ressaltar a necessidade de ações como esta sobre a temática, sendo necessário estimular o desenvolvimento de medidas preventivas, com o intuito de: promover a saúde, contribuir para a diminuição das mortes e de hospitalizações por causas externas e, consequentemente, reduzir os gastos gerados ao setor saúde resultantes desses fatores, que podem ser evitados por meio da educação em saúde.

Por fim, enfatiza-se que, embora as atividades tenham sido realizadas com população local, as características gerais das populações rurais se assemelham, mesmo em diferentes regiões do país. Portanto, acredita-se que atividades de mesmo caráter podem, e devem ser realizadas com públicos de outros municípios brasileiros. Além disso, os resultados gerados a partir desta experiência contribuem para evidenciar a importância da inserção de atividades com a população rural nos cursos de graduação em Enfermagem e também para trazer para essa população os serviços de saúde, principalmente ao que diz respeito à promoção da saúde e prevenção de agravos.

Quanto às limitações, ressalta-se o número reduzido de produtores que participaram das atividades. Ao mesmo tempo, entende-se que esse fato está relacionado às atividades e demandas da vida rural, pois, muitas vezes, os produtores acabam tendo que trabalhar nos finais de semana devido a maior carga de trabalho em períodos sazonais, como de plantio e colheita de produtos. Ademais, outra limitação deve-se ao fato de o programa de extensão não ter sido integrado a uma pesquisa concomitante. Considerando isso, sugere-se que os grupos PET associem pesquisa, ensino e extensão em suas ações.

\section{CONCLUSÃO}

A capacitação da população em primeiros socorros é indispensável para a realização do atendimento inicial em situações de emergência. Sendo assim, a sua conscientização acerca da temática se faz relevante quando se considera que o acesso precoce ao serviço especializado eleva a sobrevida, assim como a inoperância no momento de avaliação e diagnóstico da situação podem agravar ainda mais a situação.

As ações educativas dessa natureza possibilitaram a troca de saberes entre acadêmicos e comunidade, promovendo a multiplicação de conhecimento acerca das situações de emergências para os participantes. Além de propiciar aos discentes o desenvolvimento das habilidades de educador e facilitador, fundamentais para a atuação do enfermeiro.

A realização desse projeto pelos grupos PET transcende os muros da universidade, possibilitando que os conhecimentos obtidos na academia cheguem até a população, dando retorno direto à comunidade em geral. $\mathrm{A}$ partir da construção coletiva e ativa, ocorrem benefícios mútuos, em que comunidade e discentes aprenderam e compartilharam saberes para o crescimento e melhoria da saúde.

Nesse sentido, sugere-se que mais estudos e ações educativas de promoção em saúde sejam realizados, nessa temática de primeiros socorros, abrangendo as populações rurais. Justifica-se isto pelo aumento dos acidentes também em comunidades do interior, onde, muitas vezes, as intervenções iniciais são incorretas, vindas de indivíduos com pouco conhecimento, feitas com práticas baseadas no senso comum e agravam o quadro, elevando as chances de morte.

A capacitação de forma objetiva, simples e de fácil entendimento se mostra uma eficiente estratégia para capacitar as populações do interior e propiciar uma abordagem inicial correta e ágil, podendo mudar o desfecho de quem precisa de um atendimento antes da chegada ao serviço especializado. 


\section{AGRADECIMENTOS}

Ao Programa de Educação Tutorial (PET) Enfermagem da Universidade Federal de Santa Maria.

\section{CONTRIBUIÇÕES}

Caren da Silva Bertoldo, Catiele Piccin, Daiana Cristina Wickert, Jordana Lima Silva, Victória dos Quadros Severo Maciel, Oclaris Lopes Munhoz e Maria Denise Schimith contribuíram com a elaboração e delineamento do estudo; a aquisição, análise e interpretação dos dados; a redação e/ou revisão do manuscrito.

\section{FONTES DE FINANCIAMENTO}

Fundo Nacional de Desenvolvimento da Educação (FNDE).

\section{REFERÊNCIAS}

1. Ministério da Saúde (BR). Informações em Saúde. Brasília: Ministério da Saúde; 2013.

2. Andrade-Barbosa TL, Xavier-Gomes LM, Barbosa VA, Caldeira AP. Mortalidade masculina por causas externas em Minas Gerais, Brasil. Ciênc Saúde Colet [Internet]. 2013 [acesso em 2018 Abr 30];18(3):711-9. Disponível em: https://goo.gl/y4a1xc

3. Corassa RB, Falci DM, Gontijo CF, Machado GVC, Alves PAB. Evolução da mortalidade por causas externas em Diamantina (MG), 2001 a 2012. Cad Saúde Colet [Internet]. 2017 [acesso em 2018 Abril 30];25(3):302-14. Disponível em: https://goo.gl/y6SWfg

4. Gonsaga RAT, Rimoli CF, Pires EA, Zogheib FS, Fujino MVT, Cunha MB. Avaliação da mortalidade por causas externas. Rev Col Bras Cir [Internet]. 2012 [acesso em 2017 Nov 25];39(4):263-7. Disponível em: https://goo.gl/qJpZa4

5. Ragadali Filho A, Pereira NA, Leal I, Anjos QS, Loose JTT. A Importância do treinamento de primeiros socorros no trabalho. Rev Saberes [Internet]. 2015 [acesso em 2018 Abr 14];3(2):114-25. Disponível em: https://facsaopaulo.edu.br/wp-content/uploads/sites/16/2018/05/ed3/10.pdf

6. Lima RGSD. Estratégia organizacional ao atendimento de primeiros socorros nas comunidades rurais do município de Piritiba - Bahia [Internet]. São Luís: Universidade Federal do Maranhão; 2015 [acesso em 2018 Jul 15]. Disponível em: https://ares.unasus.gov.br/acervo/handle/ARES/8020

7. Silva CR, Carvalho BG, Cordoni L Jr, Nunes EFPA. Dificuldade de acesso a serviços de média complexidade em municípios de pequeno porte: um estudo de caso. Ciênc Saúde Colet [Internet]. 2017 [acesso em 2018 Jul 14];22(4):1109-20. Disponível em: http://www.scielo.br/scielo.php?pid=S1413$81232017002401109 \&$ script $=$ sci_abstract\&tIng=pt

8. Moura TVC, Araújo AL, Rosa GS, Castro JJV, Silva ARV. Práticas educativas em primeiros socorros: relato de experiência extensionista. Rev Ciênc Ext [Internet]. 2018 [acesso em 2018 Out 09];14(2):180-7. Disponível em: https://goo.gl/2gQUSy

9. Xavier SQ, Ceolin T, Echevarría-Guanilo ME, Mendieta MC. Grupos de educação em saúde: aproximação da população masculina à unidade básica de saúde. J Res Fundam Care Online [Internet]. 2015 [acesso em 2018 Jul 13];7(2):2372-82. Disponível em: https://www.redalyc.org/pdf/5057/505750946016.pdf

10. Ministério da Saúde (BR). Política nacional de redução da morbimortalidade por acidentes e violências: Portaria MS/GM n. ${ }^{\circ} 737$ de 16/5/01, publicada no DOU n. ${ }^{\circ} 96$ seção 1E de 18/5/01 [Internet]. Brasília: Ministério da Saúde, 2005 [acesso em 2018 Nov 05]. Disponível em: http://bvsms.saude.gov.br/bvs/ publicacoes/politica_reducao_morbimortalidade_acidentes_2ed.pdf

11. World Health Organization. Injuries and violence: the facts. Geneva: World Health Organization; 2014 [acesso em 2018 Nov 05]. Disponível em: https://apps.who.int/iris/bitstream/handle/10665/149798/9789241508018_ eng.pdf;jsessionid=8061D07A813C0CCA316EE9520ED41336? sequence $=1$

12. Ministério da Saúde (BR). Política Nacional de Promoção da Saúde. 3a. ed. Brasília: Ministério da Saúde; 2010 [acesso em 2018 Nov 05]. Disponível em: https://goo.gl/tSnYPB 
13. Nardino J, Badke MR, Bisogno SBG, Guth EJ. Atividades educativas em primeiros socorros. Rev Contexto Saúde [Internet]. 2012 [acesso em 2017 Out 21];12(23):88-92. Disponível em:https://www.revistas.unijui.edu. br/index.php/contextoesaude/article/view/949

14. Universidade Federal de Santa Maria. UFSM em Números [Internet]. 2018 [acesso em 2018 Nov 05]. Disponível em: https://ruf.folha.uol.com.br/2018/perfil/universidade-federal-de-santa-maria-ufsm-582.shtml

15. Costa CWA, Moura DL, Costa FLO, Mélo RS, Moreira SR. Unidade didática de ensino dos primeiros socorros para escolares: efeitos do aprendizado. Pensar Prat [Internet]. 2015 [acesso em 2018 Out 14];18(2):338-49. Disponivel em: https://www.revistas.ufg.br/fef/article/view/30205

16. Freitas TPP, Paula CC, Zanon BP, Meirelles FSC, Weiller TH, Padoin SMM. Contribuições da extensão universitária na formação de acadêmicos de enfermagem. Rev. Enferm UFSM [Internet]. 2016 [acesso em 2018 Out 09];6(3):307-16. Disponível em: https://periodicos.ufsm.br/reufsm/article/view/19966/pdf

17. Silva JK, Conceição DMM, Rodrigues GM, Dantas GSV. Suporte básico de vida para leigos: relato de atividades extensionistas. Rev Ciênc Ext [Internet]. 2017 [acesso em 2017 Jul 19];13(1):190-203. Disponível em: http://ojs.unesp.br/index.php/revista_proex/article/view/1383/1327

18. Silva NC, Nogueira LT. Avaliação de indicadores operacionais de um serviço de atendimento móvel de urgência. Cogitare Enferm [Internet]. 2012 [acesso em 2018 Jul 15];17(3):471-7.Disponível em: https:// revistas.ufpr.br/cogitare/article/view/29287

19. Fundação José Arthur Boiteux. Agrotóxicos: a nossa saúde e o meio ambiente em questão: aspectos técnicos, jurídicos e éticos. Universidade Federal de Santa Catarina [Internet]. 2012 [acesso em 2018 Jul 15]. Disponível em: http://formsus.datasus.gov.br/novoimgarq/23005/3736418_218117.pdf

20. Agência Nacional de Vigilância Sanitária. Programa de Análise de Resíduos de Agrotóxicos em Alimentos (PARA): relatório das análises de amostras monitoradas no período de 2013 a 2015 [Internet]. 2016 [acesso em 2018 Jul 15]. Disponível em: http://portal.anvisa.gov.br/documents/219201/2782895/ Relat\%C3\%B3rio+PARA/a6975824-74d6-4b8e-acc3-bf6fdf03cad0?version=1.0

21. Ministério da Saúde (BR). DATASUS. Intoxicação exógena: notificações registradas no SINAN NET-Brasil [Internet]. 2018 [acesso em 2018 Jul 15]. Disponível em: http://tabnet.datasus.gov.br/cgi/tabcgi.exe?sinannet/ cnv/lntoxbr.def

22. Ministério da Saúde (BR). Secretaria de Vigilância em Saúde. Departamento de Vigilância em Saúde Ambiental e Saúde do Trabalhador. Diretrizes nacionais para a vigilância em saúde de populações expostas a agrotóxicos. [Internet]. 2016 [acesso em 2018 Jul 14]: 26. Disponível em: http://bvsms.saude.gov.br/bvs/ publicacoes/diretrizes_vigilancia_populacoes_expostas_agrotoxicos.pdf

23. Silva JB, Xavier DS, Barboza MCN, Amestoy SC, Trindade LL, Silva JRS. Fumicultores da zona rural de Pelotas (RS), no Brasil: exposição ocupacional e a utilização de equipamentos de proteção individual (EPI). Saúde em Debate [Internet]. 2013 [acesso em 2018 Abr 10];37(97):347-53. Disponível em: http://www.scielo. br/scielo.php?script=sci_arttext\&pid=S0103-11042013000200016

24. Ministério da Saúde (BR). Secretaria de Vigilância Sanitária. Manual de vigilância da saúde de populações expostas a agrotóxicos. [Internet]. 1997 [acesso 2018 Jul 23]. Disponível em: http://bvsms.saude.gov.br/bvs/ publicacoes/livro2.pdf

25. Mello CM de; Silva LF. Fatores associados à intoxicação por agrotóxicos: estudo transversal com trabalhadores da cafeicultura no sul de Minas Gerais. Epidemiol Serv Saúde. [Internet]. 2013 [acesso em 2018 Out 15];22(4):609-20. Disponível em: http://scielo.iec.gov.br/scielo.php?script=sci_arttext\&pid $=$ S1679-49742013000400007

26. Alves JL, Almeida PMV. A Importância do ensino aprendizagem para prestação de primeiros socorros ás vítimas de choque elétrico: metodologia da problematização. Rev. Uningá [Internet]. 2017 [acesso em 2018 Abr 15];54(1):160-6. Disponível em: https://goo.gl/AMim9U

27. ABRACOPEL. Anuário Estatístico Brasileiro dos Acidentes de Origem Elétrica: Ano base 2017 [Internet]. 2018 [acesso em 2018 Abr 15]. Disponível em: http://abracopel.org/noticias/saem-os-dados-ineditos-sobreacidentes-de-origem-eletrica-de-2017/ 
28. Azevedo IC, Vale LD, Araújo MG, Cassiano AN, Silva HS, Cavalcante RD. Compartilhando saberes através da educação em saúde na escola: interfaces do estágio supervisionado em enfermagem. Rev Enferm Cent-O Min [Internet]. 2014 [acesso em 2018 Out 09];4(1):1048-56. Disponível em: http://www.seer.ufsj.edu.br/index. php/recom/article/view/565/579

\section{Endereço para correspondência:}

Caren da Silva Bertoldo

Universidade Federal de Santa Maria - UFSM

Av. Roraima, 1000 - Cidade Universitária

Bairro: Camobi

CEP: 97105-900 - Santa Maria - RS - Brasil

E-mail: carensbertoldo@gmail.com

Como citar: Bertoldo CS, Wickert DC, Maciel VQS, Piccin C, Silva JL, Munhoz OL et al. Noções básicas de primeiros socorros: relato de experiência de um projeto de extensão rural. Rev Bras Promoç Saúde. 2019;32:8255. 